\title{
Effects of Renewable Energy and Accessibility on Household's Fuel Choices: A Case Study in Kenya
}

\author{
Stephen K. Kimutai* \\ Department of Mechanical \& Production Engineering, Moi University \\ Africa Center of Excellence in Phytochemicals, Textile and Renewable Energy, Moi University, Kenya \\ P.O Box 3900, Eldoret, Kenya \\ Henry K. Kiriamiti \\ Department of Chemical \& Process Engineering, Moi University \\ Africa Center of Excellence in Phytochemicals, Textile and Renewable Energy, Moi University, Kenya \\ P.O Box 3900, Eldoret, Kenya \\ Denyse Snelder \\ Vrije Universiteit Amsterdam, Centre for International Cooperation (CIS-VU) \\ Amsterdam, Netherlands
}

\begin{abstract}
Regardless of the efforts to encourage the use of renewable energy sources such as solar and biogas in developing countries, their adoption and use is still low especially in Kenya. The purpose of this research was to investigate effects of renewable energy and accessibility on household fuel choices in Kenya among households in rural and peri-urban areas. Random sampling technique was used to select a sample of 199 households in the county of Uasin Gishu. Data for the study were collected using a structured questionnaire and analyzed using different quantitative and qualitative statistical procedures and methods. Analysis reveals that rural households are still dependent largely on kerosene and electricity for lighting their houses and majorly firewood for cooking, while electricity and charcoal form a major source of energy for lighting and cooking in peri-urban households respectively. A small portion of households in rural (11.6\%) and peri-urban (12.9\%) use biogas energy for cooking. The results also shows negative association between the use of renewable energy and the use of conventional household energy sources for cooking (firewood, kerosene and charcoal) and lighting (kerosene) implying reduction in deforestation, indoor pollution and dependency on imported fuels. Further, it was found that there is positive association between accessibility and the type of fuel used at household level for cooking indicating that nearness to diverse supplying shops selling fuel is positively associated with household energy changing behaviour. The effects of renewable energy will reduce the use of conventional fuels and household's energy diversification while accessibility on the other hand increases household fuel choices. The finding offers insights that could increase the uptake of renewable energy and reduce the problems associated with traditional fuels.
\end{abstract}

Keywords: Household energy, renewable energy, accessibility, cooking and lighting

DOI: $10.7176 / \mathrm{JETP} / 9-7-04$

Publication date:October $31^{\text {st }} 2019$

\section{Introduction}

Even though there are several initiatives promoting the use of renewable energy sources, analysis of its effects on the use as alternative energy sources and accessibility of household energy sources are limited especially in Kenya (Sarkodie \& Adom, 2018). Most of the existing literature on household energy use focus mainly on economic, social, and demographic factors (Martínez, 2014; Azam, 2016) disregarding the potential effects of renewable energy (Sugiawan \& Managi, 2016) and accessibility of conventional fuels in the household energy utilization and changing behaviour. In developing countries like Kenya, the accessibility of household energy use continues to pose a formidable challenge, especially with the high cost of cooking gas and kerosene and the environmental problems associated with firewood (Bruce, 2000; Ezzati \& Kammen, 2001 and Pode, 2010). Many people are not aware of the health and environmental effects of using charcoal, kerosene and firewood and those with little understanding have challenges of accessibility. Use of these conventional energy sources especially kerosene is implicated as a causal agent of respiratory diseases. Other diseases associated with conventional fuels include chronic obstructive pulmonary disease (COPD), asthma, cancer of the nasopharynx and larynx, tuberculosis, prenatal conditions, low birth weight, and diseases of the eye such as cataract and blindness. It is therefore, imperative that urgent interventions are needed, not only to ensure fuel accessibility but also lay the foundation for the improvement of livelihood through use of renewable energy. Currently, renewable energy development is emphasized for sustainable development goals accomplishment and the better realization of sustainable development globally. Changing to renewable energy that make use of limited natural resources with high potential of reusing and recycling at the end of their valuable life is one of the best ways of responding to the increasing 
global, national, and local environmental challenges (Berhe, Tesfahuney, Desta, \& Mekonnen, 2017). Further, renewable energy (RE) technologies play an important role in addressing the challenge of achieving environmental sustainability by providing the opportunity to meet the energy needs of the present without compromising the ability of future generations to meet their own energy needs (Surie, 2017).

Kenya, like other developing countries, is striving to adopt different ways of ensuring affordable and accessible energy supply to achieve renewable energy development. Household access to clean and affordable modern energy is also critical to improving living standards in developing countries. Energy access is achieved when a household has the opportunity to obtain sufficient quantity and quality of energy to meet the energy demands. The distance to the market selling fuels plays an important role in household's decision to choose a particular source of energy. The distance to major fuel supply infrastructure is also critical in household decision about fuel choice. The choice of firewood as the main cooking fuel is positively correlated to the distance to the most commonly used. Research done by Rahut et al, 2016 showed that there is positively associated with a household choice of firewood and negatively associated with LPG, electricity and candles, indicating that households which are further from the retail shops (market) are more likely to use traditional energy such as firewood, agricultural residues and less likely to use advanced clean energy such as LPG because of less accessibility. The choice of clean fuels, however, is negatively correlated to the distance, both of which are consistent with expectations.

Access to diversity of fuel suppliers is another important factor in energy accessibility in terms of economic, environmental, social and institutional dimension (Kucharski \& Unesaki, 2015 and Mansson et al., 2014). All sources of household energy supply are unlikely to fail at the same time. There is no known number explaining adequate diversity of suppliers (Kruyt et al, 2009), but there is potential for reducing threats such as bad weather and disturbances such as disruptions, increased cost of fuel by diversification among suppliers. Reliance on any one supplier or group of suppliers can be an energy security risk if supplies from that region are disrupted (Cohen et al, 2011 and Costantini et al, 2007). There is no magic number signaling adequate diversity of suppliers, but more diversity is generally thought to be better for accessibility. In this study, the distance between the household residence and the nearest fuel supplying shop serves as one indicator used for assessing household access to energy sources. The second indicator is the number of shops where a household at a given location can buy one or more types of fuels. The nearness of forest or wood sources and the quantity / size of these sources will also determine accessibility of the firewood and charcoal sources. Further the research analyses the effects of renewable energy on the use of conventional fuels and its relationship to accessibility.

\section{Methodology}

The study was conducted in Uasin Gishu, Kenya which is situated in the former Rift Valley Province. The study was conducted over a 2 months period between October and December 2017. Trained interviewers administered a structured questionnaire to participants during a face to face interview. The interviewers were trained on the study objectives, how to obtain informed consent and how to administer the questionnaire to get valid responses. The questionnaire was pretested before use and adjusted as required prior to study onset. In the study, the patterns of household energy utilization are analyzed. Spearman's rank correlation (nonparametric) and Pearson's R (parametric) was also used to investigate relationships among factors influencing renewable energy sources and accessibility with the households' energy consumption behavior and the number of energy sources. Data was presented in tables and graphs.

\section{Results and Discussion}

\subsection{Trends of household energy utilization}

\subsubsection{Pattern of household energy use for cooking}

Figure 1 presents reports the percentage of households by sources of energy for cooking by households. The percentage of households that use firewood for cooking increases from $74.1 \%$ in peri urban to $86.2 \%$ among the rural dwellers. Similarly, the proportion of households that use charcoal, LPG and kerosene decline from 73.7\%, $39.3 \%$ and $54.5 \%$ to $51.6 \%, 29.4$ and $28.9 \%$ respectively as we move from Peri-urban to rural. The results show that although biogas technology is spreading, it still represents a small fraction of the energy mix at local level. 


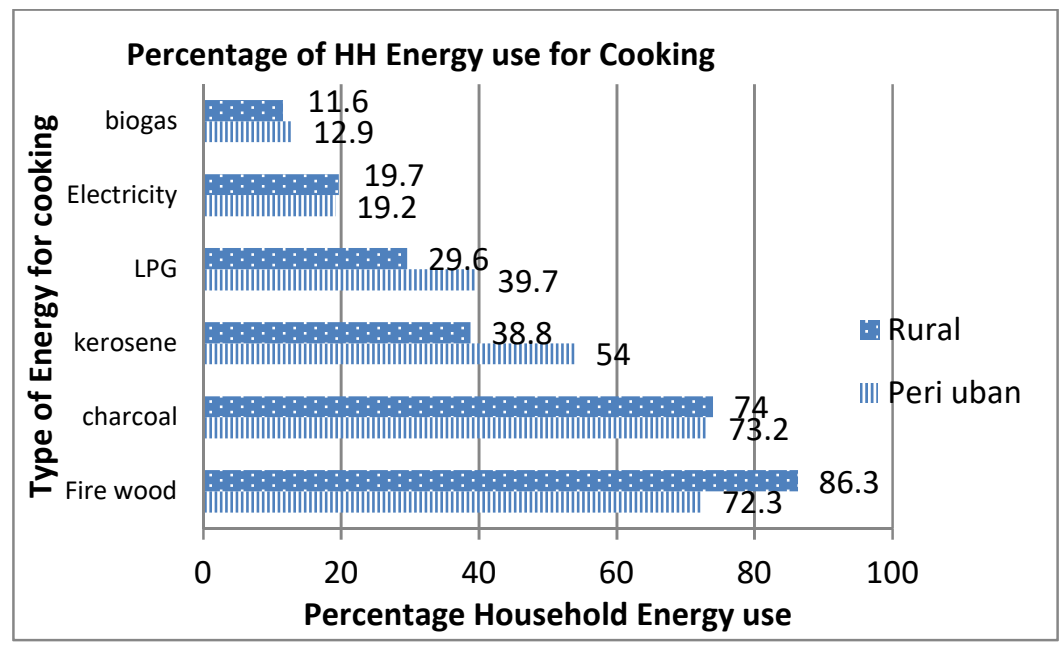

Figure 1: Energy used for cooking by households in Uasin Gishu Source: Author's (2019)

The findings of this study show that the utilization of biogas on social-economic and environment development among the local communities is low which supports the research done by Katikiro (2016).

\subsubsection{Pattern of household energy use for lighting}

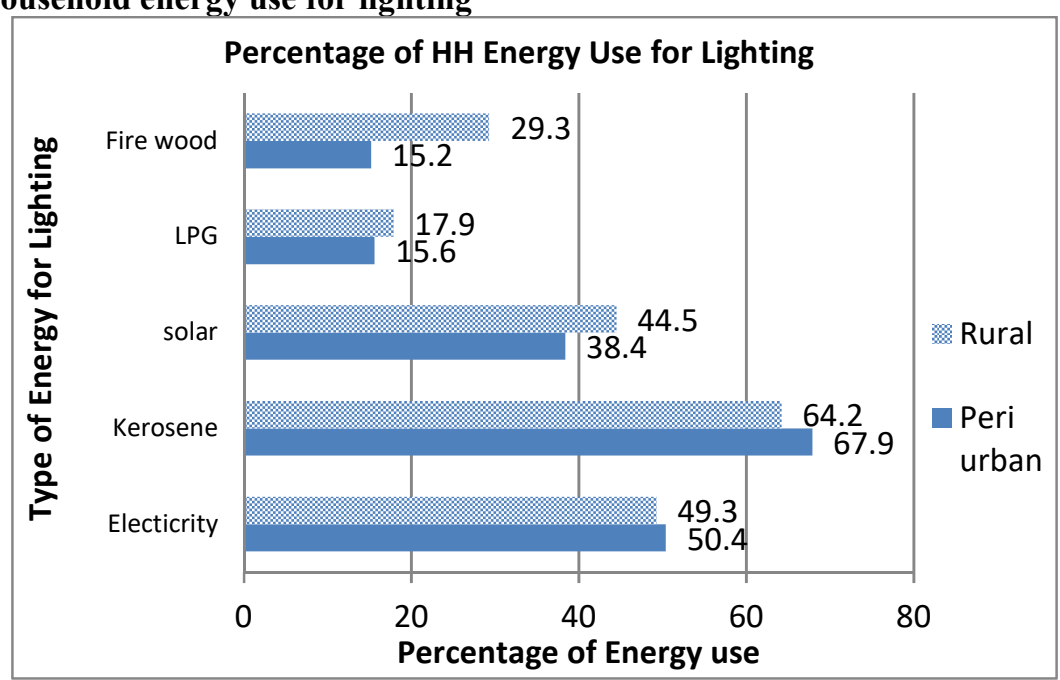

Figure 2: Energy used for lighting by households

Source: Author's (2019)

Figure 2 reports the percentage of households by sources of energy for lighting in both rural and peri urban locations. Results show a small difference between rural and peri urban households. Rural households mostly use solar lamps (44.5\%), electricity (49.3\%) and kerosene (64.2\%) as sources of energy, while Peri urban households use electricity (50.4\%), kerosene (67.9\%) and solar lamps (38.4\%). The analysis further shows an improvement in solar uptake in rural households as compared to peri -urban in Kenya. This implies there is need for awareness and accessibility for spread of solar technologies as researched by other authors such as Ondraczek (2013).

\subsection{Effects of accessibility}

\subsubsection{Distance to fuel supplying shops}

The average distance to the nearest retail shops for the purchase of firewood, charcoal and LPG is greater for households in rural areas compared to those in peri-urban areas. As one move from rural to peri-urban, indicating that peri-urban dwellers travel less distance to retail shops selling firewood, charcoal and LPG as compared to rural dwellers as shown in as shown in table 1 that reports means and standard deviation to the nearest energy selling shops. 
Table 1: Distance to retail shops selling household energy

\begin{tabular}{llllll}
\hline Area & Statistics & \multicolumn{4}{l}{ Distance to nearest supplying shop (km) } \\
\hline & & Firewood & charcoal & LPG & Kerosene \\
\hline Peri & Mean & 2.96 & 2.55 & 2.72 & .90 \\
urban & Std. Dev. & 3.96 & 3.57 & 3.87 & .73 \\
\hline Rural & Mean & 0.44 & 11.39 & 12.03 & 1.30 \\
& Std. Dev. & 4.94 & 4.84 & 6.26 & .89 \\
\hline
\end{tabular}

Source: Author's (2019)

It was found that distance to nearest retail shops selling fuel in kilometres is negatively associated with household changing behaviour to fuel choices thus indicating a reducing trend in the use of the fuels with the increase in distance of energy sources for firewood, charcoal, LPG and Kerosene in both rural and peri urban. This result concurs with Brouwer (1997).

\subsubsection{Number of different fuel supplying shops}

Peri-urban dwellers have access to greater number of fuel supplying shops in village of between 3 and 5 on average for firewood, charcoal, LPG and kerosene in contrast with rural residence as shown in table 2.

Table 2: Number of retail shops supplying household energies in the village

\begin{tabular}{lll}
\hline & Number of different fuel supplying shops in: & \\
\hline Area & Peri urban & Rural \\
Firewood & 2.97 & 0.19 \\
Charcoal & 2.83 & 0.21 \\
Kerosene & 4.43 & 3.3 \\
LPG & 2.9 & 0.26 \\
Access to electricity (\%) & 62 & 46.7 \\
\hline
\end{tabular}

Source: Author's (2019)

Table 3 shows results on correlation between the number of retail shops supplying household energies and fuel energy use.

\begin{tabular}{lll} 
& \multicolumn{3}{l}{ Spearman's correlation } \\
\hline Area & Peri urban & Rural \\
Firewood & $0.166^{* * *}$ & $0.04 * * *$ \\
Charcoal & $0.064^{* * *}$ & $0.008^{* * *}$ \\
Kerosene & $0.039^{* * *}$ & $0.038^{* * *}$ \\
LPG & $0.078^{* * *}$ & $0.039^{* * *}$ \\
Access to electricity (\%) & $0.141^{* * *}$ & $0.297 * * *$ \\
\hline \multicolumn{3}{r}{ Source: Author's (2019) }
\end{tabular}

The results indicate that there is positive association between the number of retail shops selling household energy and the type of fuel used at household level for cooking implying that nearest to diverse supplying shops selling fuel is positively associated with household changing behaviour as shown in table 3 . Accessibility to electricity also is associated with its use for cooking. It was observed that there is lack of distribution, selling points and storage facilities of LPG among rural areas hence constraining its accessibility while in the peri-urban area concentration of selling points, distributors and storage units is high. The reason that there are fewer firewood and charcoal shops in rural areas is because more than half of households in rural areas are closer farm trees for firewood which make them gather easily wood themselves as compared to households in peri-urban areas.

\subsection{Effects of Renewable energy}

\subsubsection{Effects of Biogas energy for cooking on other household energy used}

Table 4 presents results of the relationship between biogas and conventional energy sources for cooking. The results indicate negative and significant relationships between the use of biogas and the use conventional energy sources for cooking (fire wood, charcoal and kerosene), implying a reduction deforestation, indoor pollution and dependency on imported fuels with the use of biogas for cooking. This finding concurs with Shams et al., (2014). The result also shows positive relationship between biogas usage and LPG among the peri urban dwellers. The use of biogas reduces the use of traditional fuels and household's energy diversification, as well as lead to time-savings due to a reduction in time spent gathering firewood (Bedi et al, 2017). This implies that uses biogas reduces their use of firewood and charcoal leading to slows down deforestation and reduces greenhouse gas emissions. The result also shows positive relationship between biogas usage and LPG. 
Table 4: Results of correlation analysis for biogas and other sources of energy used for cooking

\begin{tabular}{|c|c|c|c|c|c|}
\hline Areas & Firewood & Charcoal & Kerosene & Electricity & $L P G$ \\
\hline Peri urban & $-0.106 * *$ & $-0.142 * *$ & -0.14 & $-0.317^{*}$ & $0.062 *$ \\
\hline Rural & $-0.307 * * *$ & $-0.213 * * *$ & $-0.121 *$ & $0.121^{*}$ & -0.046 \\
\hline
\end{tabular}

\subsubsection{Effects of solar energy for lighting on household's number of energy sources}

Table 5 reports the results of correlations on effect of solar for lighting on household energy changing behaviour. It is clear from the table that the use of solar energy for lighting is negatively and significantly associated with the use of kerosene and electricity. This implies that solar energy is substitutes indicating that to reduce kerosene use, which pose a formidable challenge especially health and the environmental problems (Muller et al, 2003), solar energy should be promoted for instance by subsidizing the prices.

Table 5: Results of correlation analysis for solar energy and other sources of energy used for lighting

\begin{tabular}{lllcl}
\hline Areas & Kerosene & LPG & Fire wood & Electricity \\
\hline Peri urban & $-0.08^{* *}$ & $0.364^{* * *}$ & 0.061 & $-0.204^{* *}$ \\
Rural & $-0.175^{*}$ & $-0.193^{* *}$ & -0.045 & $-0.121^{*}$ \\
\hline
\end{tabular}

*** Significant $1 \%, * *$ significant $5 \%$, * significant $10 \%$

Source: Author's (2019)

\subsubsection{Effect of Biogas for cooking on household's number of energy sources}

Table 6 shows the results of correlation analysis for biogas and household's number of energy sources for cooking. Biogas for cooking is negatively associated with the household's number of energy sources, indicating that biogas utilization reduces diversification.

Table 6: Results of correlation analysis for biogas and other sources of energy used for cooking

\begin{tabular}{lc}
\hline Areas & HH number of energy sources \\
\hline $\begin{array}{l}\text { Peri urban } \\
\text { Rural }\end{array}$ & $-0.42 * * *$ \\
\hline$* * *$ Significant at $1 \%, * *$ Significant at $5 \%$ and $*$ Significant at $10 \%$ \\
\end{tabular}

\subsubsection{Effect of solar for lighting on household's number of energy sources}

Table 7 shows the results of correlation analysis solar and household's number of energy sources for lighting. Solar for lighting is negatively associated with the household's number of energy sources, indicating reduced diversification on conventional fuels such as kerosene. The research also supports studies that every reduced amount in firewood and charcoal is beneficial for the people and its environment (Kimutai et al, 2014; Chodkowska and Szymańska, 2013; Smith, 2006).

Table 7: Effect of solar for lighting on household's number of energy sources

\begin{tabular}{lc}
\hline Areas & HH number of energy sources \\
\hline $\begin{array}{l}\text { Peri urban } \\
\text { Rural }\end{array}$ & $-0.39 * * *$ \\
$* * *$ Significant at $1 \%, * *$ Significant at $5 \%$ and $*$ Significant at $10 \%$ & \\
\multicolumn{2}{c}{ Source: Author's $(2019)$}
\end{tabular}

\section{Conclusion}

Biomass in the form of firewood and charcoal remain the most prominent fuel in rural and peri urban areas respectively for cooking in Kenya. The use of renewable energy reduces the use of traditional fuels and household's energy diversification, as most households without biogas/solar use multiple sources while accessibility on the other hand increases the fuel choices and the number of energy sources (diversification). The number of energy sources and the types of fuels used for cooking and lighting depend on the accessibility of households to energy sources. To improve the uptake of renewable energy sources, there is need to enhance accessibility of renewable energy technologies such biogas and solar systems in the community. The study can assist the government in formulation of energy policies that boost the use of sustainable energy resources.

\section{ACKNOWLEDGEMENT}

The author acknowledges the support from ASALI project which was funded through the legacy of Late Ms Grietje Wille

\section{References}

Azam, M., Khan, A. Q., Zafeiriou, E., \& Arabatzis, G. (2016). Socio-economic determinants of energy 
consumption: An empirical survey for Greece. Renewable and Sustainable Energy Reviews, 57, 1556-1567.

Bedi, A. S., Sparrow, R., \& Tasciotti, L. (2017). The impact of a household biogas programme on energy use and expenditure in East Java. Energy Economics, 68, 66-76.

Berhe, T. G., Tesfahuney, R. G., Desta, G. A., \& Mekonnen, L. S. (2017). Biogas Plant Distribution for Rural Household Sustainable Energy Supply in Africa,. Energy and Policy Research, 10-20.

Bisu, D. Y., Kuhe, A., \& Iortyer, H. A. (2016). Urban household cooking energy choice: an example of Bauchi metropolis, Nigeria. Energy, Sustainability and Society, 6(1), 15.

Brouwer, I. D., Hoorweg, J. C., \& Van Liere, M. J. (1997). When households run out of fuel: responses of rural households to decreasing fuelwood availability, Ntcheu District, Malawi. World development, 25(2), 255266.

Bruce, N., Perez-Padilla, R., \& Albalak, R. (2000). Indoor air pollution in developing countries: a major environmental and public health challenge. Bulletin of the World Health organization, 78, 1078-1092.

Bruce, N., Perez-Padilla, R., \& Albalak, R. (2000). Indoor air pollution in developing countries: a major environmental and public health challenge. Bulletin of the World Health organization, 78, 1078-1092.

Chodkowska-Miszczuk, J., \& Szymańska, D. (2013). Agricultural biogas plants-A chance for diversification of agriculture in Poland. Renewable and Sustainable Energy Reviews, 20, 514-518.

Cohen, G., Joutz, F., \& Loungani, P. (2011). Measuring energy security: Trends in the diversification of oil and natural gas supplies. Energy policy, 39(9), 4860-4869.

Costantini, V., Gracceva, F., Markandya, A., \& Vicini, G. (2007). Security of energy supply: Comparing scenarios from a European perspective. Energy policy, 35(1), 210-226.

Ezzati, M., \& Kammen, D. M. (2001). Indoor air pollution from biomass combustion and acute respiratory infections in Kenya: an exposure-response study. The Lancet, 358(9282), 619-624.

Katikiro, R. E. (2016). Prospects for the uptake of renewable energy technologies in rural Tanzania. Energy Procedia, 93, 229-233.

Kimutai, S. K., Muumbo, A. M., Siagi, Z. O., \& Kiprop, A. K. (2014). A study on agricultural residues as a substitute to fire wood in Kenya: a Review on Major Crops.

Kruyt, B., van Vuuren, D. P., de Vries, H. J., \& Groenenberg, H. (2009). Indicators for energy security. Energy policy, 37(6), 2166-2181.

Kucharski, J., \& Unesaki, H. (2015). A policy-oriented approach to energy security. Procedia Environmental Sciences, 28, 27-36.

Mansson, A., Johansson, B., \& Nilsson, L. J. (2014). Assessing energy security: An overview of commonly used methodologies. Energy, 73, 1-14.

Martínez-Espiñeira, R., García-Valiñas, M. A., \& Nauges, C. (2014). Households' pro-environmental habits and investments in water and energy consumption: Determinants and relationships. Journal of environmental management, 133, 174-183.

Muller, E., Diab, R. D., Binedell, M., \& Hounsome, R. (2003). Health risk assessment of kerosene usage in an informal settlement in Durban, South Africa. Atmospheric Environment, 37(15), 2015-2022.

Ondraczek, J. (2013). The sun rises in the east (of Africa): A comparison of the development and status of solar energy markets in Kenya and Tanzania. Energy Policy, 56, 407-417.

Pode, R. (2010). Solution to enhance the acceptability of solar-powered LED lighting technology. Renewable and sustainable energy Reviews, 14(3), 1096-1103.

Rahut DB, Ali A, Behera B. (2016). Domestic use of dirty energy and its effects on human health: empirical evidence from Bhutan. Int J Sustain Energy: 1-11.

Sarkodie, S. A., \& Adom, P. K. (2018). Determinants of energy consumption in Kenya: a NIPALS approach. Energy, 159, 696-705.

Shams, D. F., Qasim, A. M., Khalid, K., \& Shah, K. H. (2014). Impact of biogas on sustainable livelihood in rural areas a case study of swat, Pakistan. Journal of Applied Environmental and Biological Sciences, 4(8S), 2833.

Smith, K. R. (2006). Health impacts of household fuelwood use in developing countries. UNASYLVA-FAO-, 57(2), 41.

Sugiawan, Y., \& Managi, S. (2016). The environmental Kuznets curve in Indonesia: Exploring the potential of renewable energy. Energy Policy, 98, 187-198.

Surie, G. (2017). Achieving Sustainability: Insights from Biogas Ecosystems in India. Agriculture, 1-20. 